\title{
Interpretación y gestión del patrimonio en los espacios del turismo oscuro... ¿de qué estamos hablando?
}

\author{
Óscar Navajas Corral | Universidad de Alcalá \\ URL de la contribución <www.iaph.es/revistaph/index.php/revistaph/article/view/5095>
}

\section{"Arbeit macht frei"1 \\ "Arrête! C'est ici l'empire de la mort"2}

El turismo y el patrimonio son oscuros. Esa puede ser una de las primeras conclusiones al hacer una lectura de las diversas contribuciones que se han enviado al debate número 21 de revista $P H$. Y en realidad quizás fuese la primera "provocación" cuando en el inicio del texto para la proposición de este debate preguntábamos: "¿De qué estamos hablando cuando hablamos de patrimonio?, ¿de qué estamos hablando cuando hablamos de turismo? (...) ¿existe un lado oscuro en el patrimonio?, es decir, ¿existe un patrimonio oscuro?, ¿existe un patrimonio que suscite 'lo negativo': dolor, pena, muerte, morbo, memoria traumática, etc.?, ¿y si existe esa cara oculta de nuestro pasado quién lo añora y quién lo visita..., o quién lo consume? En otras palabras ¿cuál es el lado oscuro del turismo?" (ver texto introductorio de Navajas Corral y Rodríguez Achútegui, pp. 132-133).

En las siguientes líneas no se dará respuesta a estas preguntas, pero sí se constatarán nuevos retos y perspectivas (constructivas) de futuro.

\section{El debate epistemológico}

Los lugares donde han ocurrido hechos traumáticos y que componen parte de la memoria colectiva de nuestras sociedades contemporáneas son el eje de continuas tensiones sociales, culturales y políticas. Todo ello influye en qué se recuerda, qué se olvida y cómo se narra. Una miscelánea que configura las motivaciones para el denominado turismo oscuro que visita este tipo de patrimonios y sus espacios.
El Dark Tourism (en adelante Turismo Oscuro) es un concepto reciente, enarbolado en los años 90 por autores como Lennon y Foley (1996). Este concepto fue uno más de los que salieron de la caja de Pandora de ese lado oscuro del turismo. Así, encontramos, un turismo enfocado en el dolor y la pena (Rojek 1993); un turismo macabro (Dann 1994); un tanaturismo (Seaton 1996 2000); un turismo mórbido (Blom 2000); un turismo atroz (Ashworth 2002); un turismo de nostalgia (Stone y Sharpley 2008); un turismo de tristeza (Kurnaz, Çeken y Kiliç 2013), etc. Esta variedad se puede resumir en el análisis que presenta David González cuando afirma: "Desde una recreación kitsch a la experiencia educativa en un antiguo campo de concentración, todo es susceptible de ser analizado bajo el paradigma del turismo oscuro" (González Vázquez, pp. 176-178).

Cada una de las acepciones enumeradas dan respuesta a una motivación en la sociedad que demanda visitar y consumir -si se nos permite esta expresión- este tipo de patrimonios y experiencias. Algunas de las motivaciones son el conocimiento de la historia, la empatía con el sufrimiento humano (Sharpley y Stone 2009), la nostalgia (Cohen 2011), etc., aunque como también apunta el texto citado de González Vázquez, las inquietudes de los visitantes nos incitan a reflexionar si será consciente la propia demanda que está realizando el turismo oscuro. $Y$, desde nuestro punto de vista: ¿será consciente, simplemente, del lado oscuro del patrimonio..., y del turismo?

\section{La ética y la moral de visitar a las parcas}

¿Podemos hablar de lo "sublime"3 en el turismo oscuro? ¿Pueden llegar a un "síndrome de Stendhal"4 los "necro- 
rrománticos" (Calderón Fajardo, pp. 205-207) al ver, por ejemplo, las fortificaciones de una contienda bélica? Es cierto que una serie de fortificaciones modifican el paisaje $y$, con el tiempo, forman parte de la identidad de los territorios y sus comunidades ${ }^{5}$, pero ¿llegará el caso de que el puesto de escuadra de Los Migueles (González Meyer, pp. 208-209) pueda extasiar a un visitante como lo hizo con el escritor francés la Santa Croce de Florencia? En realidad, ¿qué diferencia un búnker de una iglesia, un palacio, etc.? No es un secreto afirmar que en estos últimos lugares hubo belleza, creación, magnificencia, pero también hubo atrocidades, vejaciones, muerte y "asfixia".

Es cierto, sin embargo, que este tipo de lugares, patrimonios y museos del turismo oscuro siempre se encuentran ligados a una problematización del presente (Mora Hernández 2013, 100). La memoria traumática y, en concreto, la visita (turística) a estos espacios está asociada a la contemporaneidad viva de la memoria indi- vidual y colectiva. En EE.UU., la patrimonialización y musealización de la tragedia del 11S; en América Latina, los espacios asociados a la dictaduras militares y conflictos sociales y armados; en España, la guerra civil y la dictadura.

Esta presencialidad en la memoria actual es lo que puede suponer que actividades turísticas enfocadas en desarrollar acciones para conocer espacios patrimoniales con una carga traumática (pena, dolor, muerte, morbo, etc.), desde un punto vista antropológico, como apunta Maximiliano Korstanje, hagan del turismo oscuro algo diferente y que posea, por otro lado, el potencial de establecer vínculos empáticos con las tragedias, las frustraciones, el dolor, las vejaciones, etc., sufridas por el Otro ${ }^{6}$. Una variable que se disipa cuando vistamos, por ejemplo, un museo de bellas artes o una catedral. Para este autor, el dilema de esta tipología entonces se encuentra en algo más a largo plazo. Este tipo de

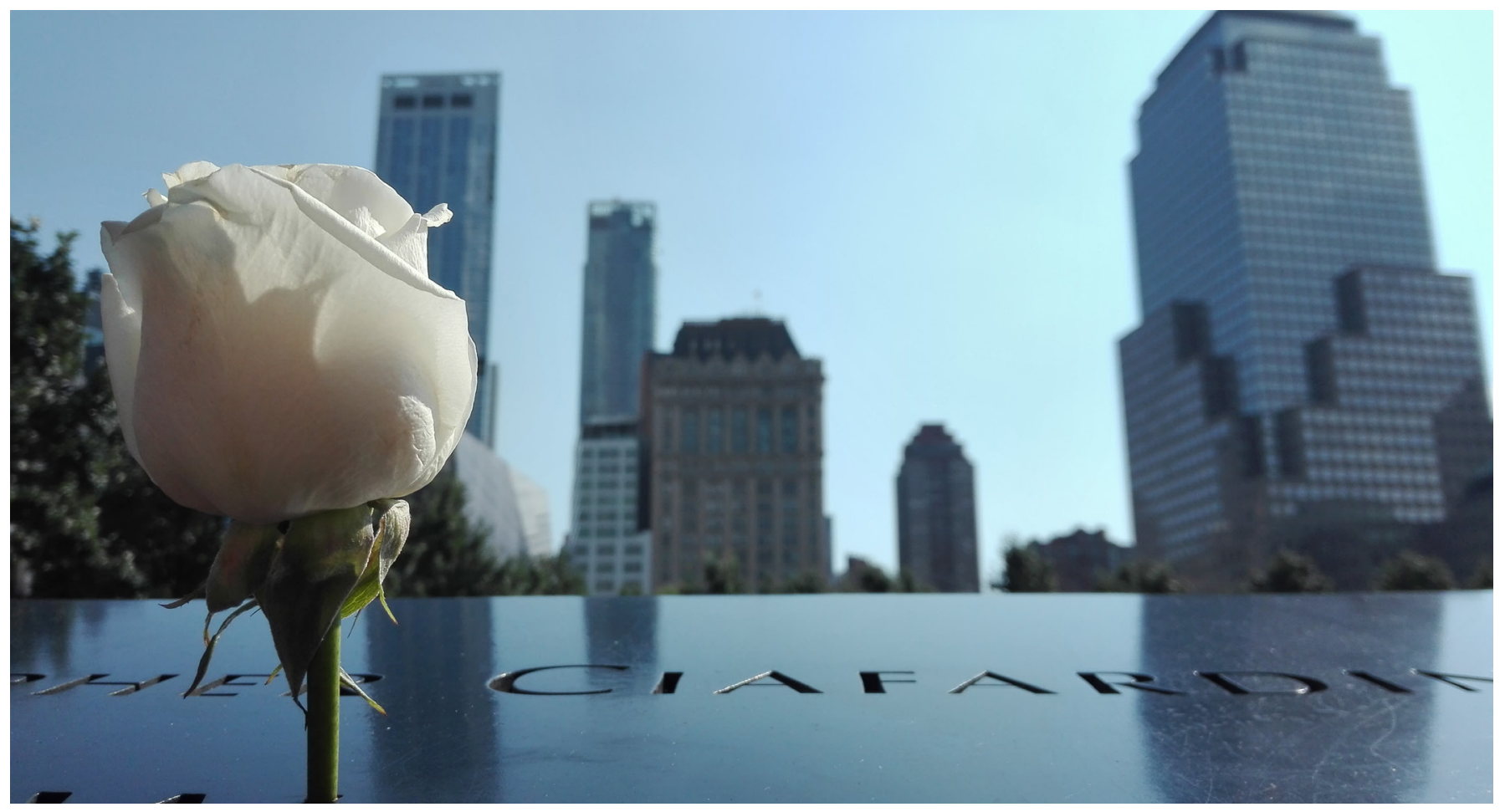

Memorial 11S | foto Álvaro Marques Hijazo 


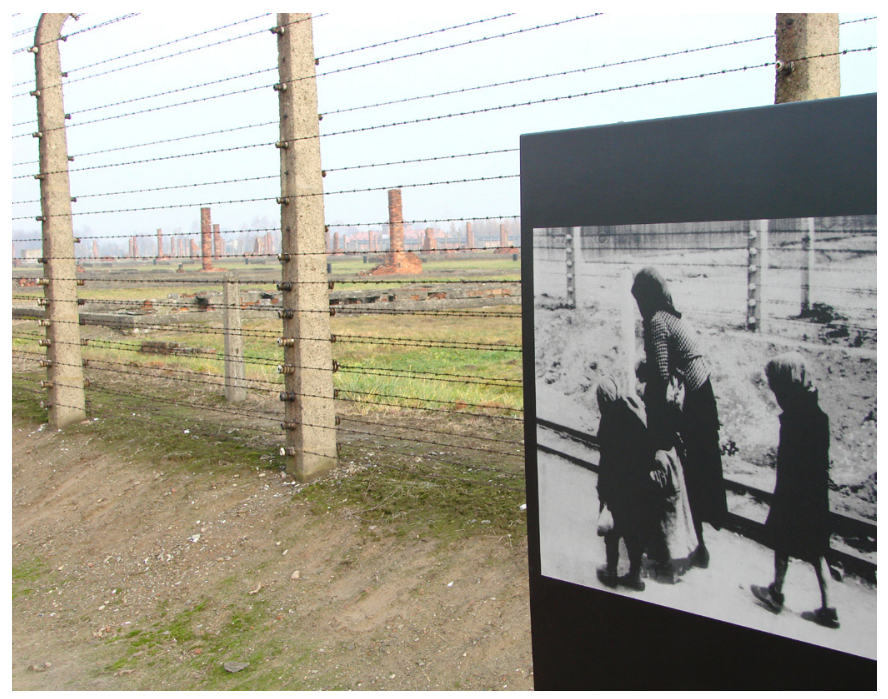

Campo de concentración de Auschwitz con foto de familia judía en la ruta a la cámara de gas | foto Adam Jones

turismo está poniendo en tela de juicio el propio "placer" y otium del viaje turístico: "La muerte del 'otro' nos genera placer porque por medio de ese ritual continuamos estando vivos".

Unos nuevos planteamientos que incitan a pensar en dónde están los límites en la "presentación" y "exhibición" del trauma, o cuáles son sus objetivos: recuperar la memoria, reparación, ideología, nostalgia, lucro, pedagogía, valores, etc. La visión amable del concepto de patrimonio es tan subjetiva como ucrónica, al mismo tiempo que es tan real como social. En este debate si algo se ha planteado es lo inefable que resulta pensar el patrimonio en positivo, cuando lo que verdaderamente contiene los bienes es una diversidad de relatos e imaginarios que lo que muestran son la esencia del ser humano, su paso a través de la historia.

Es por ello que quizás el turismo oscuro no tenga que existir como categoría o subcategoría dentro del sector, y su cometido sea el de romper las ataduras de las narraciones unidireccionales y de la colonialidad (Mignolo 2003), es decir, como apunta Sergio Ramos Cebrián: "el concepto de Dark Tourism presenta una oportunidad para romper las jerarquías patrimoniales". Es posible, como apuntamos en su momento con Tomislav Šola, que el patrimonio deba comenzar a generar relatos sobre " $(. .$. desesperación, dolor, miedo, rabia, culpabilidad, soledad, pena, angustia, dificultades, peligros"; y comprender que quienes ocupan el espacio de los imaginarios con los que hemos construido nuestra historia y nuestra memoria (individual y colectiva) "(...) eran (también) taimados, maliciosos, traidores, vengativos, insolentes, abyectos, crueles, malvados, sesgados, posesivos, avariciosos, parciales, corruptos, lujuriosos, lúbricos, escandalosos, ladrones, criminales, impúdicos, arteros, mentirosos, bribones, sucios, ruidosos, indolentes, indóciles, traviesos, inmoderados, envidiosos, perjuros (...) (2012: 137). Carmen Ortiz García, en esta misma línea, nos recuerda y enfatiza con autores como Deloche, Šola o Benjamin, que “(...) la barbarie, la destrucción y la guerra están permanente y esencialmente presentes, en el análisis de la construcción social del patrimonio".

\section{Interpretar y comunicar el lado oscuro del patrimonio} Viendo esta disonancia diletante entre un turismo oscuro que quizás no deba existir y los bienes patrimoniales que son en esencia oscuros, nos resta por plantearnos cómo podemos poner en valor la oscuridad del patrimonio, es decir, cómo generar discursos para que el patrimonio -en general- pueda mirarse como bienes y no como repositorios estereotipados de historia(s), ideología(s) o grandeza(s).

Para que esto suceda se hace necesario una descolonización objetual, así como una revisión en la jerarquía en la toma de decisiones de aquello que se patrimonializa y de cómo se interpreta (Brulon 2020). El turismo oscuro o la puesta en valor de la "oscuridad" del patrimonio nos enfrenta a una de las caras de la cosmética del capitalismo que evita y disfraza: la muerte. Esto, como muestra la contribución de Korstanje mencionada anteriormente, corre el riesgo de la banalización ${ }^{7}$ y la comercialización. Quizás, como cuestiona Júlia Faria: “¿por qué hemos llegado a la mercantilización de lugares con una historia ligada a acontecimientos traumáticos? ¿Para quién y por qué se conservan, clasifican y musealizan?". Rescatando las motivaciones de la demanda que se han 
apuntado al principio y si las analizamos, las estrategias de patrimonialización y musealización se han enfocado en los aspectos históricos y emocionales, pero aún no han potenciado, en palabras de Josu Santamarina Otaola, "estimular la empatía, la denuncia colectiva o la reflexión crítica". Posiblemente sea el momento de terminar con el "turismo de Holocausto" e iniciar un turismo pedagógico, como apunta en su contribución Cristina Martínez Fraile, donde consideramos que los mensajes a transmitir deben ser: (1) la no violencia, (2) la cultura ciudadana, (3) la justicia social y la paz, (4) la reparación del sentido y concepto de Humanidad.

Estos aspectos nos adentran en la complejidad de la puesta en valor de un hecho traumático del pasado por medio del conocimiento y la memoria desde el presente, es decir, desde la posmemoria (Hirsch 2008). El patrimonio se fundamenta en las investigaciones de las ciencias sociales y humanas, pero vive, se nutre y necesita de la memoria individual y colectiva. Los procesos de reconstrucción de esa memoria es uno de los retos de la interpretación y puesta en valor de estos patrimonios y sus espacios. En esos procesos de posmemoria se mezclan recuerdos, olvidos, realidades, mitificaciones e incluso

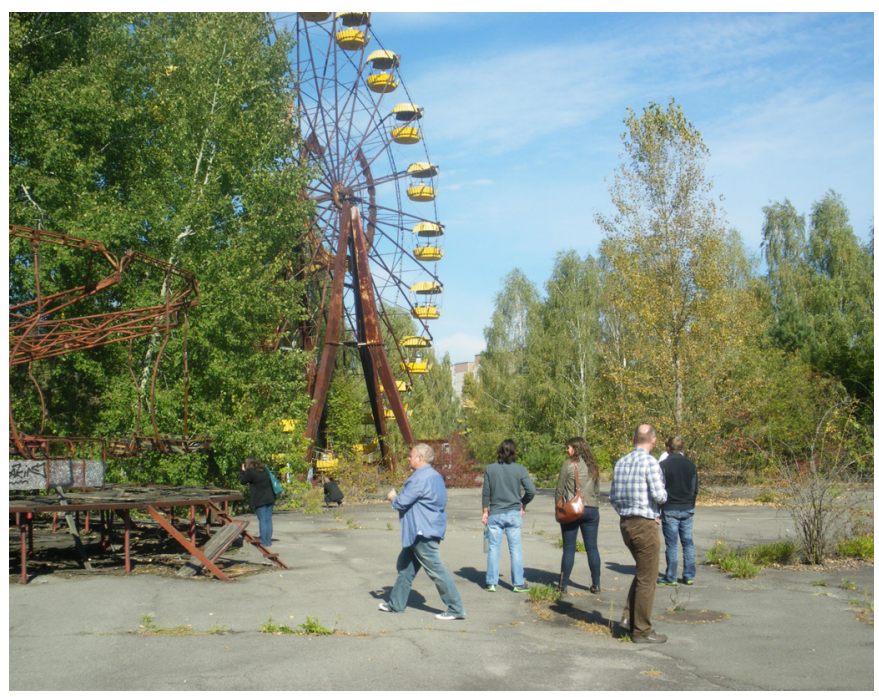

Turistas en el parque de atracciones de Chernobil en Pripyat, Ucrania | foto Jayne Cravens falsedades como señala Alfonso Hidalgo Mañero; y todos ellos son voces narrativas del pasado que poseen su sitio y, por supuesto, deben ser distinguidas y explicadas, es decir, necesitan, como compartimos con Fabien Van Geert, de un proceso de negociación que excluya la negación e incluya la pluralidad de voces ${ }^{8}$.

Este panorama no hace más que potenciar la idea de que la definición de patrimonio deje de estar relegada a la esfera de lo material para hacer referencia a lo inmaterial, es decir, a las emociones, los sentimientos, las costumbres, las ideologías, los estereotipos, etc.; y, en algunos casos, esto se traduce en dolor, pena, intolerancia (y tolerancia), humillación, dignidad, olvido, perdón, o vergüenza. Una simbiosis perfecta para contextualizar la ruptura de la definición de patrimonio instituida y que nos acerca a la idea de espacios de memoria traumática (Arrieta 2016; Navajas Corral y González Fraile, 2019). Un aspecto que, en la contribución de Carmen Ortiz reseñada, se justifica como una distinción con el turismo oscuro al relacionarse con una voluntad de justicia y reconciliación con un nosotros actual y contemporáneo.

La puesta en valor de estos patrimonios sería la aceptación política y social de la culpabilidad (Ricoeur 2000), la redención o la "vergüenza" de un pasado reciente y traumático. Incluso podemos llegar a plantear el debate de la utilización del turismo como elemento ideológico y jerarquizante con un patrimonio como el traumático. No es algo nuevo, como recuerda Saida Palou en el caso de España, "el patrimonio fue un pretexto y el turismo un instrumento útil" en el caso de la Guerra Civil Española.

Independientemente de poder atisbar un futuro en el que romper la colonialidad patrimonial, aún tenemos una "deuda" con el pasado doloroso. Josu Santamarina Otaola en su texto nos subraya que el panorama de patrimonializaciones dentro de ese denominado turismo oscuro también está evidenciando y visualizando los silencios sobre otros espacios y patrimonios olvidados (Boyarin 1989) o negados (Míguez Macho 2018). En un sentido similar y que completa esto, Antonio Bellido apunta que "no abundan en España 'museos de la ver- 


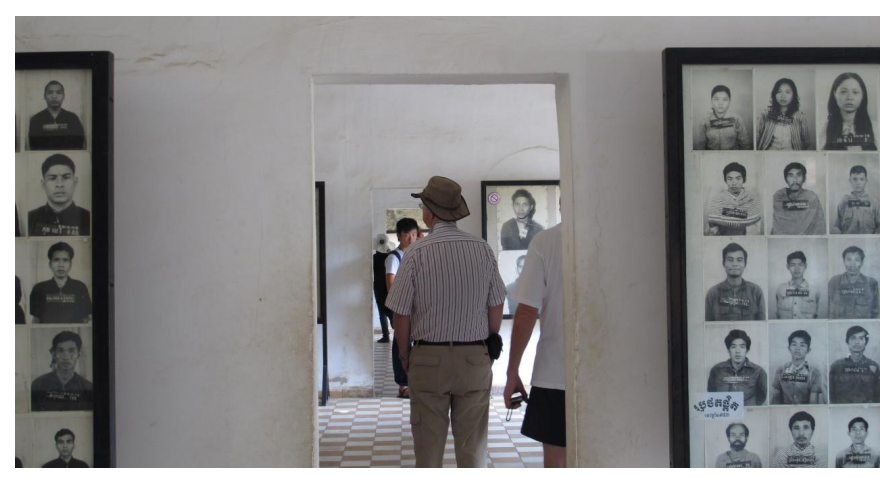

Visita al Tuol Sleng, museo del genocidio, Phnom Penh (Camboya) | foto Los viajes del Cangrejo

güenza', de aquellos que pretenden incitar a la reflexión y obligar a considerar los pasos en falso y los errores de los pueblos"; pero, por el contrario, sus contenidos nos hablan de esa otra cara nefasta de la Historia y de las historias de nuestro pasado. Continuamos visitando y reproduciendo de forma indirecta e inconsciente una colonialidad cultural desde lo instituido, algo que Sergio Ramos nos recuerda en su contribución como el epistemicidio (De Sousa 2017), mediante los discursos impuestos por el poder político (Hartmann 2014) y los que fueron silenciados.

\section{Consideraciones finales}

Tras un cuarto de siglo de vida del concepto de turismo oscuro, David González en su texto plantea las incógnitas que aún posee un fenómeno que, por contra, está generando un considerable volumen de teorías, publicaciones y proyectos desde el mundo académico e investigador, así como una diversidad de ofertas de productos turísticos y de motivaciones para la visita por parte de la demanda. Si bien sigue sin estar claro si existe una conexión entre la Academia y la realidad del sector, ni siquiera si esta tipología es simplemente el reflejo de la coyuntura por la que atraviesan nuestras sociedades contemporáneas.

El camino del turismo oscuro acaba de comenzar, pero su futuro es tan incierto como prometedor. Por un lado, crece y se diversifica la oferta al mismo tiempo que aumenta la demanda. Por otro lado, la visibilización de esta tipología turística nos ofrece una reflexión sobre los propios bienes patrimoniales, su jerarquía y las narrativas que sobre ellos se han construido. Como ejemplo, el texto de Adrià Besó que muestra los procesos de significación y resignificación del pueblo de Belchite tras la Guerra Civil Española. El patrimonio, oscuro o no, no deja de ser un elemento neutro generado por la interacción del ser humano y su entorno en el que socialmente construimos y otorgamos valores, historias, estética, memoria..., pero también olvidos, silencios, frustraciones, miedos, vergüenza, etc. Debemos empezar a asumir todos los aspectos polifónicos del poliedro que supone un bien patrimonial y aprender, como apuntan Cecilia del Socorro y Elena María Pérez, que todas las voces son bienvenidas.

\section{NOTAS}

1. "El trabajo os hará libres" es la frase que se colocaba en la entrada de los campos de concentración de la Alemania nazi.

2. Los turistas que visitan las catacumbas de París se encuentran con esta frase justo al entrar en ellas: "¡Detente! Es aquí el imperio de la muerte".

3. Interesante leer el texto de este debate de Francisco Delgado Chica (pp. 179-182).

4. La visita a espacios patrimonializados como cementerios posee motivaciones que se encuentran dentro de lo estético y la historia del arte. Carmen Haro Cáceres y Paula Resta Serrano señalan en este debate (pp. 200-201) cómo acudir a algunas de estas necrópolis tiene como objetivo visitar a personas famosas, algo que vincula de forma paradigmática vida, muerte y fastuosidad; o como el acercamiento a una obra de arte o a un monumento.

5. Para la importancia de este patrimonio territorial es relevante leer el texto de Alberto Atanasio y Jorge Moya sobre los búnkeres del siglo XX (pp. 173-175).

6. La propia visita a cementerios es un acto existencialista que nos acerca a la muerte y a la eternidad, a la 
visión material de nuestra realidad inmediata y a la abstracción espiritual con nuestros antepasados. Para estos planteamientos consultar el texto de Sara Filipa dos Reis (pp. 202-204).

7. Existen numerosos ejemplos de esta banalización. Se puede leer un ejemplo en la contribución de Francisca Ramón. Este texto es interesante leerlo junto con la vivencia descrita en esta sección por Víctor Manuel Fernández Martínez.

8. Numerosos de los procesos de patrimonialización de patrimonios y espacios de memoria traumática se han visibilizado gracias al impulso de colectivos que hicieron de un patrimonio incómodo un imaginario de historia común y de identidad. Recomendamos en este sentido el texto de Óscar Olivares Álvarez y Javiera Bustamante Danilo (pp. 190-192).

\section{BIBLIOGRAFÍA}

- Arrieta, I. (ed.) (2016) Lugares de memoria traumática. Bilbao: Universidad del País Vasco

- Ashworth, G.J. (2002) Review of Dark Tourism: The Attraction of Death and Disaster. By J. Lennon and M. Foley. Tourism Management, vol. 23, n. ${ }^{\circ} 2$, pp. 190-91

- Blom, T. (2000) Morbid Tourism: A Postmodern Market Niche with an Example from Althorpe. Norwegian Journal of Geography, n. ${ }^{\circ}$ 54, pp. 29-36

- Boyarin, J. (1989) Un lieu de l'oubli: le Lower East Side des Juifs. Communications, n. ${ }^{\circ} 49$, pp. 185-193

- Brulon Soares, B. (2020) Introducción. Descolonizando la museología: la experiencia museística contada en los tiempos de las comunidades. En: Brulon Soares, B. (ed.) Descolonizando a Museología, 1. Museos, Acción Comunitaria y Descolonización. Paris: Icom/Icofom, pp. 30-50

- Cohen, E.H. (2011) Educational dark tourism at an in populo site: The Holocaust Museum in Jerusalem. Annals of tourism research, vol. 38, n. ${ }^{\circ}$ 1, pp. 193-209

- Dann, G.M. (2000) Differentiating Destinations in the Language of Tourism: Harmless Hype or Promotional Irresponsibility? Tourism Recreation Research, vol. 25, n. ${ }^{\circ} 2$, pp. $63-75$

- De Sousa, B. (2017) Justicia entre Saberes. Epistemologías del Sur contra el epistemicidio. S.I.: Ediciones Morata

- Foley, M., y Lennon, J.J. (1996b) Special issue: dark tourism. International Journal of Heritage Studies, vol. 2, n. ${ }^{\circ} 4$, pp. 194244

- Hartmann, R. (2014) Dark tourism, thanatourism, and dissonance in heritage tourism management: New directions in contemporary tourism research. Journal of Heritage Tourism, vol. 9, n. $^{\circ} 2$, pp. $166-182$

- Hirsch, M. (2008) The generation of postmemory. Poetics Today, vol. 29, n. ${ }^{\circ}$, pp. 103-128

- Kurnaz, H.A., Çeken, H. y Kiliç, B. (2013) Determination of Dark Tourism Participants' Travel Motivations. Journal of Business Research Turk, 5/2, pp. 57-73

- Mignolo, W. (2003) Historias locales/diseños globales. Colonialidad, conocimientos subalternos y pensamiento fronterizo. Madrid: Ed. Akal

- Míguez Macho, A. (2018) Un pasado negado. Lugares de violencia y lugares de memoria del golpe, la guerra civil y el franquismo. Confluenze. Rivista di Studi Iberoamericani, vol. 10, n. ${ }^{\circ}$ 2, pp. $127-151$

- Mora Hernández, Y. (2013) Lugares de memoria: entre la tensión, la participación y la reflexión. Panorama, vol. 7, n.ำ 13, pp. 97-109

- Navajas Corral, O. y González Fraile, J. (2019) Interpretación y comunicación del patrimonio de la Guerra Civil Española. Herramientas y metodologías para aplicar en la Comunidad de Madrid. En: García, M.A., Baquedano, I. y Pastor, F.J. (coord.) Plan regional de fortificaciones de la Guerra Civil (1936-1939) de la Comunidad de Madrid. Madrid: Dirección General de Patrimonio de la Comunidad de Madrid, pp. 139-174

- Seaton, A.V. (1996) Guided by the dark: from thanatopsis to thanatourism. International Journal of Heritage Studies, vol. 2, n. ${ }^{\circ} 4$, pp. $234-244$

- Seaton, A. V. (2000) Another weekend away looking for dead bodies. Tourism Recreation Research, vol. 25, n. ${ }^{\circ} 3$, pp. 63-77

- Sharpley, R. y Stone, P.R. (ed.) (2009) The darker side of travel: The theory and practice of dark tourism. Bristol: Channel view Publications

- Stone, P. y Sharpley, R. (2008) Consuming dark tourism: A thanatological perspective. Annals of tourism Research, vol. 35, n. ${ }^{\circ}$ 2, pp: $574-595$

- Ricoeur P. (2000) La mémoire, l'histoire, l'oubli. Paris: Le Seuil

- Rojek, C. (1993) Ways of Escape: Modern Transformations in Leisure and Travel. London: Palgrave Macmillan

- Šola, T. (2012) La eternidad ya no vive aquí. Un glosario de pecados museísticos. Girona: ICRPC Llibres 